\title{
Staging of the cognitive decline in Alzheimer's disease: insights from a detailed neuropsychological investigation of mild cognitive impairment and mild Alzheimer's disease
}

\author{
Stephen F. Carter ${ }^{1,2}$, Diana Caine ${ }^{3}$, Alistair Burns ${ }^{4}$, Karl Herholz ${ }^{2}$ and Matthew A. Lambon Ralph ${ }^{1}$ \\ ${ }^{1}$ Neuroscience and Aphasia Research Unit (NARU), School of Psychological Sciences, University of Manchester, UK \\ ${ }^{2}$ Wolfson Molecular Imaging Centre, University of Manchester, UK \\ ${ }^{3}$ Department of Neuropsychology, National Hospital for Neurology and Neurosurgery, London, UK \\ ${ }^{4}$ Medical and Human Sciences, University of Manchester, UK \\ Correspondence to: Dr S. Carter, E-mail: Stephen.f.carter@manchester.ac.uk
}

\begin{abstract}
Objective: The decline of episodic memory in Alzheimer's disease (AD) is well established, but the exact appearance and staging of deficits in other cognitive domains is sometimes contentious. The current investigation attempted to elucidate the appearance of additional cognitive deficits in the nonepisodic domains and to understand these deficits with respect to the known pathological staging of $\mathrm{AD}$.
\end{abstract}

Methods: A cross-sectional investigation compared cognitively normal age-matched controls with patients with mild $\mathrm{AD}$ and mild cognitive impairment (MCI) using a detailed neuropsychological assessment.

Results: The systematic investigation of cognitive performance across the major cognitive domains demonstrates that the appearance of additional cognitive deficits in MCI and AD can be predicted, with impaired semantic cognition performance pre-empting the appearance of attention/executive dysfunction and visuospatial deficits in the majority of patients with MCI.

Conclusions: This progressive pattern of cognitive deficits fits with the known pathological staging of $\mathrm{AD}$, and the data further highlight the relative rarity of pure amnestic MCI. These results indicate that any neuropsychological test battery used to assess patients with MCI should include language and semantic memory tests in addition to typical episodic memory tests, as changes within this domain might be a sensitive indication of incipient AD. Copyright (C) 2011 John Wiley \& Sons, Ltd.

Key words: Alzheimer's disease; mild cognitive impairment; pathological staging; cognitive staging; episodic memory; semantic cognition

History: Received 18 October 2010; Accepted 24 March 2011; Published online 25 May 2011 in Wiley Online Library (wileyonlinelibrary.com).

DOI: $10.1002 /$ gps.2738

\section{Introduction}

Mild cognitive impairment (MCI) is now commonly accepted to reflect an Alzheimer's disease (AD) prodrome, specifically amnestic MCI (Dubois et al., 2007). The criteria for presence and staging of the cognitive deficits associated with both mild $\mathrm{AD}$ and $\mathrm{MCI}$, however, are contentious. Understanding the link between neuropathology and neuropsychology is key to understanding the cognitive deficits of $\mathrm{AD}$ in its earliest stages. Accordingly, a brief review of the three key neuropathological changes (amyloid deposition, neurofibrillary tangle formation and loss of cholinergic innervation) is first provided. We then consider what these might predict about the staging of cognitive decline in $\mathrm{AD}$.

Abnormal aggregation and deposition of amyloid- $\beta$ $(A \beta)$ is neurotoxic leading to neurodegeneration (Braak and Braak, 1991). Amyloid- $\beta$ deposition follows a distinct pattern in which regions of the medial temporal lobe (MTL) become hierarchically involved (Thal et al., 2000; Thal et al., 2002). Amyloid deposits are first found in the temporal neocortex and sequentially spread to the entorhinal cortex (ErC), followed 
by the subiculum/CA1 and finally the CA4 hippocampal subfield. Intraneuronal neurofibrillary tangles (NFTs) are neurotoxic to their host neuron (Bancher et al., 1989; Braak and Braak, 1991, 1998; Santacruz et al., 2005). The distribution of NFTs, like amyloid deposition, can be hierarchically characterised, and NFT formation correlates with both the degree of $A \beta$ pathology and the gradual decline in cognitive functions (Braak and Braak, 1991; Sassin et al., 2000; Shoghi-Jadid et al., 2002; Thal et al., 2002). Early NFT-related changes occur in the basal forebrain and spread to the hippocampal formation, amygdala and neocortical regions (Bancher et al., 1996; Sassin et al., 2000; Shoghi-Jadid et al., 2002). Both patients with $\mathrm{MCI}$ and AD can have NFT and amyloid pathology in the hippocampus and ErC (Troncoso et al., 1996; Price and Morris, 1999; Petersen et al., 2006).

Cholinergic dysfunction is also strongly associated with $\mathrm{AD}$. The basal nucleus of Meynert is a predilection site affected very early in AD by NFTs (Whitehouse et al., 1982; Coyle et al., 1983). The cholinergic projections from the basal forebrain to the neocortex and thalamus are fundamental in controlling attention, modulating cortical information processing and conscious awareness (Baxter and Chiba, 1999; Perry et al., 1999).

It is well established that lesions to the MTL can induce amnesia (Fleischman and Gabrieli, 1999; Scoville and Milner, 2000). The primary MTL structures of interest for $\mathrm{AD}$ include the hippocampus, the $\mathrm{ErC}$, the perirhinal cortex and the parahippocampal gyrus. The functional roles of the hippocampus include intermediate term memory storage, memory consolidation, spatial processing, cross-modal associations and recollection (Squire and Zola-Morgan, 1991; Eichenbaum et al., 1994; McClelland et al., 1995). The MTL regions outlined are also integrated within a larger MTL-memory network. Connected regions include the amygdala, the thalamus, the mamillary bodies, the posterior cingulate cortex, the temporal cortex and the medial frontal cortex (Aggleton and Brown, 1999, 2006).

The pathological hallmarks of AD clearly affect the MTL-memory network in the disease's earliest stages (Figure 1 displays the key regions involved in the MTL-memory network that are affected by $\mathrm{AD}$ pathology). The idea that pathology and neurodegeneration affect cognition is supported by both structural magnetic resonance and positron emission tomography (PET) imaging findings. A study by Wilson et al. (1996) demonstrated that hippocampal volume in patients with $\mathrm{AD}$ was positively correlated with delayed story recall performance. Hypometabolism of the temporoparietal and posterior cingulate cortices measured by FDG-PET is a routinely found phenomenon in patients with MCI and AD (Herholz, 2003). The neocortical hypometabolism matches the observed

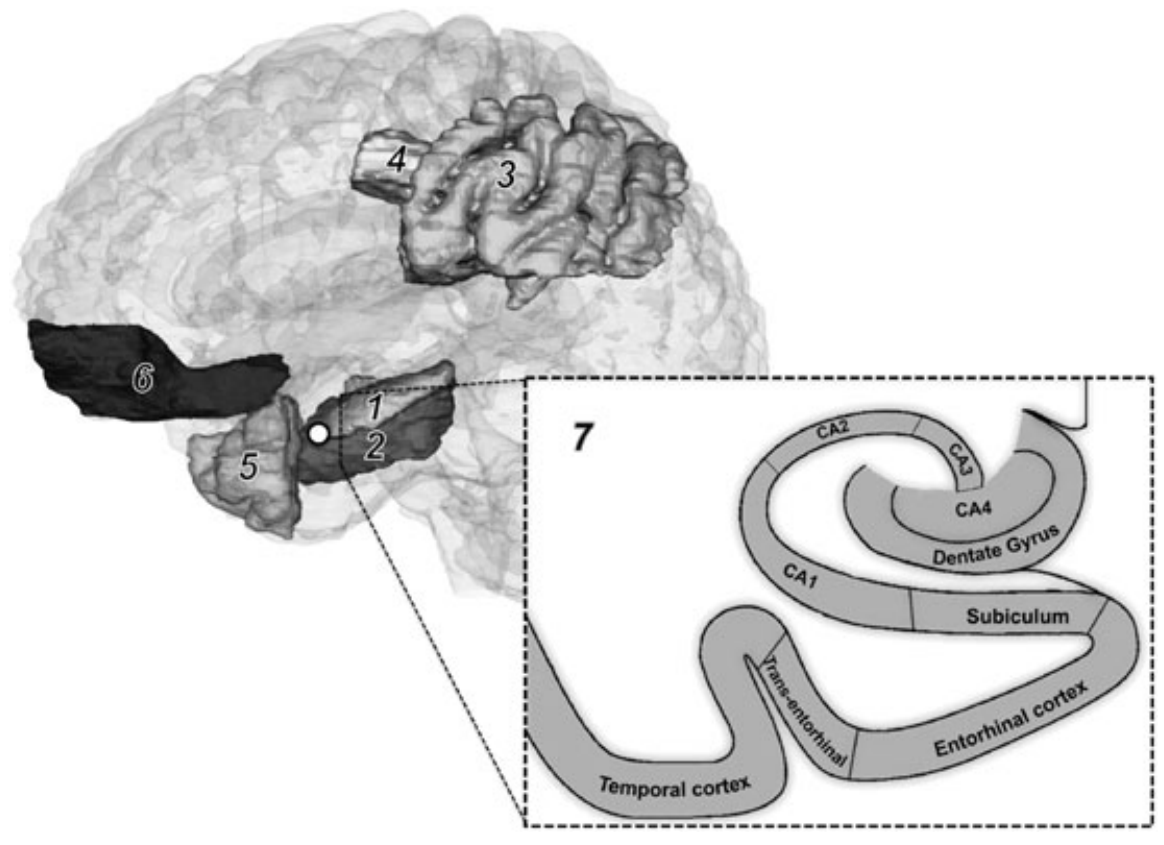

Figure 1 Regions involved in the pathological progression and neuropsychological dysfunction of Alzheimer's disease (1) Hippocampus: (2) parahippocampal gyrus; (3) temporoparietal cortex; (4) posterior cingulate cortex; (5) anterior temporal lobe; (6) medial prefrontal cortex; and (7) cross section of the MTL displaying the regions were the earliest NFT and A $\beta$ pathology begins. White circle positioned at the anterior hippocampus represents the basal nucleus of Meynert from which most of the neocortex receives its cholinergic innervation. 
clinical symptoms of $\mathrm{AD}$, which include impairments of memory and associative thinking (Herholz et al., 2007). Numerous pathological, volumetric and PET based studies demonstrate a clear link between the episodic memory impairment of $\mathrm{AD}$ and changes throughout the brain (Deweer et al., 1995; Fox et al., 1996; Stout et al., 1999; Edison et al., 2007; Jack et al., 2008).

Beyond the MTL-memory network, two candidate cognitive domains have been suggested to be impaired early in $\mathrm{AD}$. These impairments potentially reflect the pathological progression reviewed earlier. The first candidate domain is impairment of semantic cognition. Semantic dysfunction has been related to temporal neocortical volume but not to hippocampal volume (Wilson et al., 1996). Although the anatomical locus of language deficit in $\mathrm{AD}$ is often debated, it is consistent with pathological progression to anterior and lateral aspects of the temporal lobes. These regions are associated with semantic memory (Hodges and Patterson, 1995; Garrard et al., 1998; Mummery et al., 1999). When semantic memory has been comprehensively tested in patients with $\mathrm{MCI}$, it is impaired relative to controls. Mild AD patients have an even more pronounced semantic impairment, suggesting a link with disease severity and pathological locus (Hodges and Patterson, 1995; Hodges et al., 2006; Ahmed et al., 2008; Lonie et al., 2008).

Other investigations have suggested that attention/ executive functions become impaired early in $\mathrm{AD}$. In a review of the $\mathrm{AD}$ literature on attention and executive deficits (Perry and Hodges, 1999), it was suggested that, after the amnestic stage, attention might be the first non-memory domain affected, before semantic cognition and visuospatial deficits. Both neurodegeneration of the MTL and of the basal forebrain and/or a disconnection of the attentional cortical regions, along with loss of cholinergic innervation have been provided as neuroanatomical explanations for attention deficits (Parasuraman and Nestor, 1993; Baxter and Chiba, 1999; Perry et al., 1999; Bohnen et al., 2003). Neurofibrillary and $A \beta$ pathology affect regions that support attention (fronto-parietal regions, including the dorsolateral prefrontal cortex, parietal lobes, anterior cingulate cortex, thalamus and basal ganglia). Perry et al. (2000) demonstrated heterogeneity in performance between different classifications of $\mathrm{AD}$. Moderate patients with $\mathrm{AD}$ were impaired on all attentional tasks, and minimally impaired patients demonstrated selected deficits. A meta-analysis incorporating 47 studies (Backman et al., 2005) investigating the cognitive impairment in preclinical $\mathrm{AD}$ also suggested that deficits in executive functioning and perceptual speed closely follow episodic impairment.
Typically, visuospatial functions are only affected once $\mathrm{AD}$ has fully progressed; however, some patients demonstrate visuospatial deficits early and before other domains (Caine and Hodges, 2001).

The link between MTL lesions and episodic memory deficits in many MCI and mild AD patients is not disputed. What is less clear is the sequence in which other cognitive domains become dysfunctional. It is possible that as the disease spreads to the neocortical regions in the anterior temporal lobes (ATL), semantic cognition should be impaired next. Alternatively, cholinergic impairment of the neocortex occurs early during disease progression, so it is not unreasonable to expect attention and informationprocessing speed to be affected first, before semantic cognition. The aim of the present cross-sectional investigation was to provide evidence about which cognitive domains become affected after episodic memory and to test a comprehensive neuropsychological battery that can detect these cognitive changes in an old-age memory clinic.

\section{Materials and methods}

\section{Participants}

Thirteen cognitively normal $(\mathrm{CN})$ controls, 17 patients with $\mathrm{MCI}$ and 15 patients with mild $\mathrm{AD}$, participated in this investigation that was approved by the Central Manchester Research Ethics Committee (UK). All patients (and their carers/next of kin) gave signed, informed consent. All patients were recruited consecutively without selection bias from those presenting at the memory clinic within Wythenshawe Hospital, Manchester, UK. Patients with mild AD and MCI were classified as such following clinical evaluation at a consensus committee involving old age psychiatrists, clinical neuropsychologists and specialist research nurses. Patients with mild AD had a Mini mental state examination (MMSE) score of $\leq 25$ and fulfilled the criteria developed by the National Institute of Neurological and Communicative Disorders and StrokeAlzheimer's Disease and Related Disorders Association (NINCDS-ADRDA) (McKhann et al., 1984). Patients with MCI had MMSE scores of $\geq 26$; the classification of MCI was determined on the basis of the criteria established by Petersen (2004), and they did not meet the NINCDS-ADRDA criteria. Individuals with alcoholism, previous head injury, stroke, epilepsy, other neurological disease or major medical illness (e.g. cancer, thyroid dysfunction, anaemia, etc.) were excluded, as were those with an unstable psychiatric illness; patients 
with stable treated depression were included. Patients underwent brain imaging (CT scan and EEG) as well as the usual blood screening tests to exclude treatable causes of dementia. All patients from both groups were living without institutional support. All the patients with $\mathrm{AD}$ were being treated with cholinesterase inhibitors in this investigation.

For this investigation, participants underwent extensive neuropsychological investigation that was separate from their normal clinical evaluation. Wherever possible, neuropsychological testing was done in a single session. However, as this was not always feasible, particularly with the patients with mild $\mathrm{AD}$, the test battery would be completed over two sessions. Testing sessions were never more than 4 weeks apart.

\section{Materials}

Global cognition. The Addenbrooke's Cognitive Examination-Revised (ACE-R) (Mioshi et al., 2006), is a detailed measure of global cognition that tests various cognitive domains, including some (e.g. delayed recall) not included in the MMSE. It consists of five sub-components: (1) attention and orientation (/18); (2) memory (immediate and delayed recall of a name and address, measures of retrograde memory: /26); (3) verbal fluency (letter and category: /14); (4) language (repetition, comprehension and naming: /26); and (5) visuospatial function (/16). The ACE-R has a maximum score of 100 and incorporates the MMSE (Folstein et al., 1983) so that it is possible to simultaneously obtain an MMSE score.

Episodic memory tests. The Face Place Test (FPT) (Dudas et al., 2005) involves participants looking at pictures of faces, some of which are famous (politicians, actors/TV personalities and singers) and others are non-famous. The FPT assesses several different aspects of declarative memory; familiarity, recognition, spatial memory and semantic memory. The maximum score for the FPT is 100 .

Other standard episodic memory tests included: the story recall task taken from the Wechsler memory scale-III (Wechsler, 1997), the California Verbal Learning Test (Delis et al., 1987) and recall of the Rey Complex Figure Test (RCFT) (Meyers and Meyers, 1995).

Language/semantic memory tests. Letter fluency, category fluency (Garrard et al., 2001) and the Graded Naming Test (McKenna and Warrington, 1983) were administered. Components of the ACE- $\mathrm{R}$ and the FPT also give measures within the domains of language and semantic function (Table 2).
Executive/attention tests. Two tasks were adopted from the Test of Everyday Attention (Robertson et al., 1994): elevator counting with distraction and map search. The first is an auditory task with a maximum score of 10, and the second is a timed visual search task with a maximum score of 80 . Both parts of the digit span task (forward and reverse) were taken from the Wechsler memory scale-III (Wechsler, 1997). A simplified version of the Stroop (Trenerry et al., 1989) paradigm was adopted. Participants' reading speed was measured first (by reading aloud the names of colours printed on a sheet), then in the same amount of time ( $45 \mathrm{~s}$ ), they were asked to name as many incongruent colours as possible (e.g. the word 'red' printed in blue ink). The Stroop score was determined by simply calculating, as a percentage, the number of items read aloud in the incongruent condition as a proportion of the individuals' baseline reading speed. The Wisconsin Card Sorting Test (Nelson, 1976) was administered to the participants, and the number of successful category shifts was recorded. The attention and orientation component from the ACE-R was also incorporated into this domain.

Visuospatial tests. The RCFT-copy and the ACE-R visuospatial components were used as visuospatial measures. The RCFT-copy test involves participants drawing the Rey complex figure (maximum score $=$ 36); there is minimal demand placed on memory during the copy condition. The visuospatial subcomponent of the ACE-R involves participants copying pictures (e.g. interlocking pentagons) or drawing from memory (e.g. a clock face with a specific time). The visuospatial subcomponent of the ACE-R has a total score of 16.

\section{Results}

All data analyses were performed with PASW 18.0 for Mac (IBM Corporation, Somers, NY, USA). Basic demographic data for the three groups can be seen in Table 1. There was no significant difference between the groups for age and education. For the neuropsychological battery, equal variances were not assumed and Tamhane's T2 post hoc testing was used for investigating inter-group differences. Tamhane's T2 is a conservative pairwise comparison test used when equal variances are not assumed.

The mean scores, standard deviations, $F$ and $p$ values (ANOVA) for the main group effect are summarised in Table 2. Figure 2 illustrates each group's performance on the ACE-R (error bars represent +/- $1 \mathrm{SD}$ ). The 
Table 1 Descriptive statistics for basic demographic information

\begin{tabular}{|c|c|c|c|c|c|c|}
\hline & \multicolumn{2}{|c|}{$\mathrm{CN}$} & \multicolumn{2}{|c|}{$\mathrm{MCl}$} & \multicolumn{2}{|c|}{$A D$} \\
\hline & Mean & $\mathrm{SD}$ & Mean & $\mathrm{SD}$ & Mean & SD \\
\hline Age & 73.5 & 4.7 & 73.3 & 9.7 & 77.3 & 5.6 \\
\hline Gender (M/F) & $5 / 8$ & & $10 / 7$ & & $5 / 10$ & \\
\hline Years of education & 13.2 & 3.5 & 11.8 & 3.7 & 10.7 & 2.5 \\
\hline MMSE & $29.5^{\mathrm{b}, \mathrm{c}}$ & 0.52 & $28.0^{a, c}$ & 1.5 & $22.3^{a, b}$ & 3.5 \\
\hline
\end{tabular}

There was a significant group difference for MMSE score $F(2,42)=45.3 p=<0.001$. MMSE, Mini mental state examination; CN, cognitively normal; MCI, mild cognitive impairment; AD, Alzheimer's disease.

${ }^{\text {a }}$ Significantly different to $\mathrm{CN}$.

bSignificantly different to MCI.

'Significantly different to $\mathrm{AD}$.

Table 2 Means and standard deviations for neuropsychological test scores

\begin{tabular}{|c|c|c|c|c|c|c|c|c|}
\hline & \multicolumn{2}{|c|}{$\mathrm{CN}$} & \multicolumn{2}{|c|}{$\mathrm{MCl}$} & \multicolumn{2}{|c|}{$A D$} & \multirow[b]{2}{*}{$F(2,42)$} & \multirow[b]{2}{*}{$p$} \\
\hline & Mean & SD & Mean & SD & Mean & SD & & \\
\hline Total ACE-R & $95.4^{\mathrm{b}, \mathrm{c}}$ & 3.2 & $80.1^{\mathrm{a}, \mathrm{c}}$ & 10.4 & $63.5^{\mathrm{a}, \mathrm{b}}$ & 11.6 & 39.8 & $<0.001$ \\
\hline \multicolumn{9}{|l|}{ Episodic memory } \\
\hline ACE-memory & $23.7^{\mathrm{b}, \mathrm{c}}$ & 1.8 & $16.4^{\mathrm{a}, \mathrm{c}}$ & 4.7 & $7.9^{\mathrm{a}, \mathrm{b}}$ & 2.9 & 72.1 & $<0.001$ \\
\hline FPT & $91.6^{\mathrm{b}, \mathrm{c}}$ & 4.9 & $76.7^{\mathrm{a}, \mathrm{c}}$ & 14.5 & $58.3^{\mathrm{a}, \mathrm{b}}$ & 12.0 & 28.9 & $<0.001$ \\
\hline FPT-familiarity & 19.2 & 1.1 & 17.9 & 2.6 & 17.7 & 2.2 & 1.8 & ns \\
\hline FPT-recognition & $39.3^{b, c}$ & 0.6 & $36.7^{\mathrm{a}, \mathrm{c}}$ & 3.6 & $30.3^{a, b}$ & 7.0 & 14.5 & $<0.001$ \\
\hline FPT-placing & $17.5^{\mathrm{b}, \mathrm{c}}$ & 1.7 & $12.8^{\mathrm{a}, \mathrm{c}}$ & 6.0 & $7.0^{\mathrm{a}, \mathrm{b}}$ & 3.9 & 19.4 & $<0.001$ \\
\hline STOREC-immediate & $48.4^{\mathrm{b}, \mathrm{c}}$ & 7.9 & $29.2^{\mathrm{a}, \mathrm{c}}$ & 13.1 & $11.9^{\mathrm{a}, \mathrm{b}}$ & 6.8 & 46.9 & $<0.001$ \\
\hline STOREC-delayed & $30.3^{\mathrm{b}, \mathrm{c}}$ & 7.6 & $12.4^{\mathrm{a}, \mathrm{c}}$ & 11.9 & $0.1^{\mathrm{a}, \mathrm{b}}$ & 0.5 & 44.8 & $<0.001$ \\
\hline RCFT-delayed & $19.6^{\mathrm{b}, \mathrm{c}}$ & 7.9 & $11.2^{\mathrm{a}, \mathrm{c}}$ & 7.4 & $3.4^{\mathrm{a}, \mathrm{b}}$ & 4.6 & 19.9 & $<0.001$ \\
\hline CVLT & $9.8^{\mathrm{b}, \mathrm{c}}$ & 2.4 & $6.8^{\mathrm{a}, \mathrm{c}}$ & 2.6 & $3.6^{\mathrm{a}, \mathrm{b}}$ & 1.3 & 27.1 & $<0.001$ \\
\hline CVLT-delayed & $10.5^{\mathrm{b}, \mathrm{c}}$ & 3.5 & $4.9^{\mathrm{a}, \mathrm{c}}$ & 3.8 & $0.2^{\mathrm{a}, \mathrm{b}}$ & 0.6 & 31.6 & $<0.001$ \\
\hline Digit span-forwards & 6.3 & 1.1 & 5.5 & 1.5 & 5.4 & 1.1 & 2.3 & ns \\
\hline \multicolumn{9}{|l|}{ Language/semantic memory } \\
\hline ACE-fluency & $12.5^{\mathrm{b}, \mathrm{c}}$ & 1.1 & $9.6^{\mathrm{a}, \mathrm{c}}$ & 2.7 & $6.7^{\mathrm{a}, \mathrm{b}}$ & 3.5 & 16.3 & $<0.001$ \\
\hline ACE-language & $25.5^{\mathrm{c}}$ & 0.9 & 23.9 & 2.9 & $22.7^{\mathrm{a}}$ & 3.5 & 5.5 & $<0.01$ \\
\hline FPT-naming & $15.6^{\mathrm{b}, \mathrm{c}}$ & 3.7 & $9.2^{\mathrm{a}, \mathrm{c}}$ & 6.2 & $4.7^{\mathrm{a}, \mathrm{b}}$ & 4.6 & 16.2 & $<0.001$ \\
\hline FAS-total & $50.2^{\mathrm{b}, \mathrm{c}}$ & 10.4 & $38.6^{\mathrm{a}, \mathrm{c}}$ & 13.7 & $25.6^{a, b}$ & 9.9 & 15.6 & $<0.001$ \\
\hline Category fluency-total & $98.4^{\mathrm{b}, \mathrm{c}}$ & 14.5 & $69.1^{\mathrm{a}, \mathrm{c}}$ & 18.2 & $45.2^{\mathrm{a}, \mathrm{b}}$ & 15.7 & 36.7 & $<0.001$ \\
\hline Graded naming & $26.1^{\mathrm{b}, \mathrm{c}}$ & 1.9 & $19.4^{\mathrm{a}}$ & 7.2 & $16.5^{\mathrm{a}}$ & 10.2 & 5.9 & $<0.01$ \\
\hline \multicolumn{9}{|l|}{ Attention/executive } \\
\hline ACE-attention and orientation & $17.9^{c}$ & 0.3 & $17.7^{\mathrm{c}}$ & 0.7 & $14.1^{\mathrm{a}, \mathrm{b}}$ & 2.6 & 28.4 & $<0.001$ \\
\hline Digit span-backwards & $4.1^{\mathrm{c}}$ & 1.1 & $3.8^{\mathrm{c}}$ & 1.1 & $2.7^{\mathrm{a}, \mathrm{b}}$ & 0.7 & 7.0 & $<0.01$ \\
\hline TEA-map search & $46.7^{c}$ & 16.6 & 41.1 & 22.2 & $28.5^{\mathrm{a}}$ & 16.9 & 4.4 & $<0.05$ \\
\hline TEA-elevator counting & $8.2^{c}$ & 2.6 & 6.3 & 2.9 & $4.3^{a}$ & 2.8 & 6.8 & $<0.01$ \\
\hline STROOP-words & $87.5^{c}$ & 16.8 & 63.1 & 28.8 & $56.3^{a}$ & 22.3 & 7.8 & 0.01 \\
\hline STROOP-colours & $33.5^{\mathrm{b}, \mathrm{c}}$ & 10.8 & $27.8^{\mathrm{a}, \mathrm{c}}$ & 23.6 & $9.9^{a, b}$ & 11.6 & 15.2 & $<0.001$ \\
\hline STROOP-percentage & $37.6^{\mathrm{c}}$ & 8.0 & $31.1^{\mathrm{c}}$ & 19.0 & $11.6^{\mathrm{a}, \mathrm{b}}$ & 8.2 & 15.2 & $<0.001$ \\
\hline WCST-category shifts & 3.3 & 1.3 & 2.3 & 1.4 & 2.5 & 5.5 & 0.4 & ns \\
\hline \multicolumn{9}{|l|}{ Visuospatial } \\
\hline RCFT-copy & $34.5^{c}$ & 2.5 & 30.4 & 8.4 & $24.2^{\mathrm{a}}$ & 10.2 & 5.9 & $<0.01$ \\
\hline ACE-visuospatial & 15.5 & 0.9 & 14.1 & 3.1 & 13.3 & 2.8 & 2.8 & ns \\
\hline
\end{tabular}

Superscript letters indicate significant pairwise comparisons revealed by post hoc testing (Tamhane's T2, $p<0.05$ ). ns = not significant. ACE-R, Addenbrooke's Cognitive Examination-Revised; ACE, Addenbrooke's Cognitive Examination; FPT, Face Place Test; RCFT, Rey Complex Figure Test; CVLT, the California Verbal Learning Test; TEA, Test of Everyday Attention; WCST, the Wisconsin Card Sorting Test.

${ }^{a}$ Significantly different to $\mathrm{CN}$.

${ }^{\mathrm{b}}$ Significantly different to MCI.

'Significantly different to $\mathrm{AD}$. 


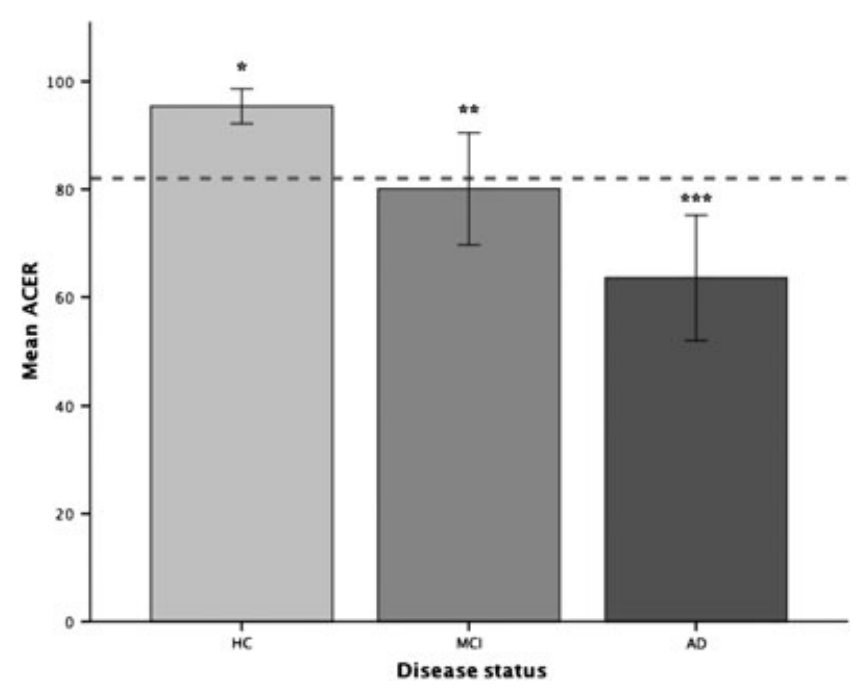

Figure 2 Bar chart displaying mean scores for the ACE-R. The difference between groups is significant $F(2,42)=39.8, p=<0.001$, post hoc testing reveals a three-way group difference $(\mathrm{CN}>\mathrm{MCI}>\mathrm{AD})$. * indicates significantly different to $\mathrm{MCI}$ and $\mathrm{AD}$; ** significantly different to $\mathrm{CN}$ and $\mathrm{AD}$; *** significantly different to CN and MCI. Error bars represent +/-1 SD. The dotted reference line (ACE-R score of 82) is a cut-off point for incipient dementia that gives $84 \%$ sensitivity and $100 \%$ specificity (based on 63 controls aged 52-75 years and 146 patients with dementia aged $46-86$ years Mioshi et al., 2006).

group difference was significant for both the ACE-R and the MMSE. Post hoc testing revealed that, for both measures, each group was significantly different from each other.

\section{Episodic memory}

Most tests revealed a hierarchical performance, which followed $\mathrm{CN}>\mathrm{MCI}>\mathrm{AD}$. The two exceptions to this pattern were the FPT familiarity component and the forward digit span, which revealed no significant group effect.

\section{Language/semantic memory}

All the semantic cognition tests revealed an overall group effect. The total category fluency, letter fluency, the fluency component of the ACE-R and the FPT naming subcomponent significantly separated the three groups such as $\mathrm{CN}>\mathrm{MCI}>\mathrm{AD}$. The graded naming test, revealed a significant inter-group difference as follows: $\mathrm{CN}>\mathrm{MCI}=\mathrm{AD}$. The less demanding language component of the ACE-R only revealed a group difference between $\mathrm{CN}$ and patients with $\mathrm{AD}$.

\section{Attention/executive}

Both the attention and orientation component of the ACE-R and the backwards digit span revealed significant inter-group differences $(\mathrm{CN}=\mathrm{MCI}>\mathrm{AD})$. The elevator counting with distraction and the map search only significantly separated the $\mathrm{CN}$ and patients with AD. For the Stroop tests, each component revealed a significant group effect, although only the incongruent condition significantly separated the three groups $(\mathrm{CN}>\mathrm{MCI}>\mathrm{AD})$. There was no group effect for the Wisconsin Card Sorting Test.

\section{Visuospatial}

The RCFT-copy and the ACE-R visuospatial measures revealed that only the RCFT-copy revealed a group effect. It significantly separated the $\mathrm{CN}$ and the patients with $\mathrm{AD}$.

\section{Mild cognitive impairment heterogeneity}

Using the current comprehensive neuropsychological test battery, it is possible to determine a more specific individual MCI profile. When using the tests from each domain that had the largest group effect and significantly separated the three groups (ACE-R memory, category fluency, stroop-colours and the RCFT-copy; Figure 3), 15 were impaired ( $>1.5$ SD below control mean) on the ACE-R memory. From this small MCI sample, only two patients met Petersen et al.'s (Petersen et al., 2001) criteria for pure amnestic MCI; the majority of patients $(N=13)$ were characterised as amnestic multiple domain MCI. 


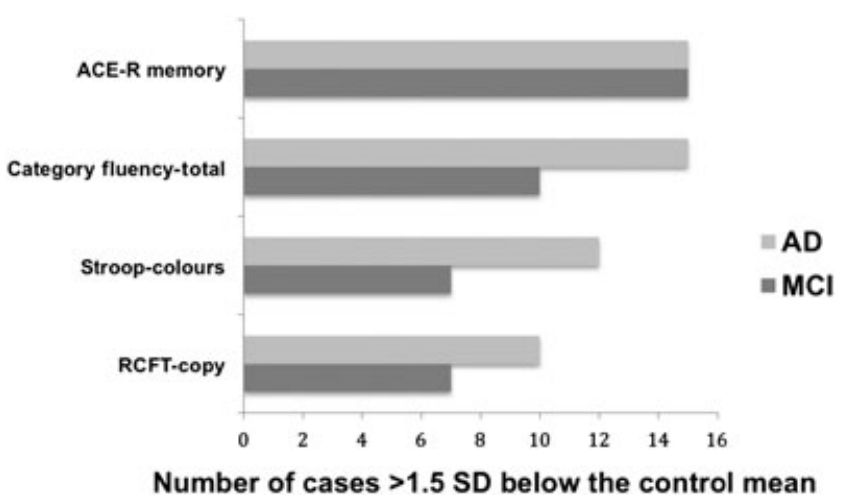

Figure 3 Bar chart displaying the heterogeneity of MCI. Bar chart displays the number of cases, more than 1.5 SD below the control mean, for the tests within each cognitive domain that had the largest group effect and were the most sensitive at significantly separating the three groups (see Table 2).

\section{Discussion}

This systematic, cross-sectional investigation of the performance of controls, MCI and patients with mild $\mathrm{AD}$ demonstrates that following episodic memory deficits, deficits in semantic cognition performance pre-empt the appearance of attention/executive dysfunction and visuospatial impairment in the majority of patients. Only two patients with MCI could be characterised as having pure amnestic MCI. The remainder were characterised as multi-domain MCI (Figure 3). This finding is supported by other studies (Ahmed et al., 2008; Lonie et al., 2008; Libon et al., 2010) and highlights the relative rarity of pure amnestic MCI.

The idea that pathology affecting the MTL leads to dysfunctional episodic memory in MCI and patients with $\mathrm{AD}$ is supported by the current investigation as the vast majority of tests revealed a significant group effect. The FPT, in particular, demonstrated that the patients had deficits in all subcomponents, except familiarity. This finding fits with the pathological staging of $\mathrm{AD}$ as pathology spreads from the $\mathrm{ErC}$ to the hippocampus and beyond (Braak and Braak, 1991; Thal et al., 2000; Thal et al., 2002; Petersen et al., 2006). In addition to the FPT, the $\mathrm{AD}$ group was also impaired on both verbal and visuospatial episodic memory tasks; this might reflect the further spread of pathology to regions outside the MTL including the parietal and anterolateral aspects of the temporal lobe.

Regions outside the MTL have also been implicated in the episodic memory network. Metabolic reductions have been found in the medial thalamus and mamillary bodies in patients with mild $\mathrm{AD}$ and MCI (Nestor et al., 2003b). The retrosplenial and posterior cingulate cortices are also functionally important to declarative memory function (Gron et al., 2000;
Deckersbach et al., 2006; Ries et al., 2006; Vann et al., 2009) and are hypometabolic in patients with MCI and AD (Kennedy et al., 1995; Minoshima et al., 1997; Drzezga et al., 2003; Ouchi et al., 2004). Nestor et al. (2006) showed that the episodic memory impairments in $\mathrm{AD}$ are related to a dysfunction (atrophy and hypometabolism) of the MTL-memory network. It is likely that the posterior cingulate is lesioned in both the current patients with MCI and mild AD.

All semantic cognition tests revealed group differences; only the ACE-language and graded naming test did not significantly separate the three groups. The semantic cognition deficits could be explained by pathological progression to the ATL (Braak and Braak, 1991; Hodges and Patterson, 1995). There is neuropsychological and neuroimaging evidence to suggest that the failures of semantic cognition in the patients with $\mathrm{MCI}$ and $\mathrm{AD}$ are associated with loss of two cognitive processes, which are dependent on ATL, frontal and temporoparietal integrity (Devlin et al., 2000; Jefferies and Lambon Ralph, 2006; Stopford et al., 2008; Corbett et al., 2009; Visser et al., 2010). These two processes include loss of amodal semantic representations from the ATL and loss of semantic control, regulated by the temporoparietal regions. Support for this suggestion comes from the fact that hypometabolism of the temporoparietal and posterior cingulate cortex is regularly found very early in $\mathrm{AD}$ (Minoshima et al., 1997; Herholz, 2003; Nestor et al., 2003b; Nestor et al., 2006; Herholz et al., 2007). In addition to its role in episodic memory, the posterior cingulate has also recently been implicated in semantic cognition (Binder et al., 2009). The finding of a breakdown in semantic cognition is consistent with the $\mathrm{AD}$ staging hypothesis (Braak and Braak, 1991; Thal et al., 2000; Thal et al., 2002) as the initial NFT pathology spreads to the ATL, which is probably 
associated with the breakdown in the amodal semantic store, and $A \beta$ is deposited throughout the neocortex including the temporoparietal and frontal regions, which become hypometabolic.

Consistent with the suggestion of impaired executive function in mild $\mathrm{AD}$ was this group's performance on the reverse digit span, which recruits working memory processes. The patients with $\mathrm{AD}$ performed worse than both the MCI and control group on this test. The performance on the incongruous condition of the Stroop followed $\mathrm{CN}>\mathrm{MCI}>\mathrm{AD}$. The fact that the Stroop-colours test was the only assessment that patients with MCI were impaired on relative to controls, suggests that the attention system in these patients is minimaly affected. Perry et al.'s (2000) patients with mild AD demonstrated deficits in all their measures of attention, with the exception of the map search test; this was not the case in the current investigation. The dysfunction in the current patients with $\mathrm{AD}$ fits with the idea of significant cholinergic dysfunction, which are typically found in studies of acetylcholinesterase activity in AD (Herholz, 2008). Some neuropathological studies indicate preserved cholinergic function particularly in MCI (Davis et al., 1999; Gilmor et al., 1999; DeKosky et al., 2002). It is possible that deficits in attention and in attentionally demanding executive tasks can only be detected as the cholinergic system has become sufficiently impaired in mild AD. The fact that all the patients with $\mathrm{AD}$ received cholinesterase inhibitors might have compensated their attention/ executive function scores. In spite of this possibility, the patients with AD still had the worst performance on all tests. Because the patients with MCI were not receiving these medications and had generally preserved function within this domain, the potential effect of cholinesterase inhibition is not deleterious to the overall conclusions.

Alzheimer's disease is a heterogeneous syndrome. Heterogeneous cognitive profiles have been previously identified in $\mathrm{AD}$ and MCI populations (Lambon Ralph et al., 2003; Snowden et al., 2007; Stopford et al., 2007; Stopford et al., 2008; Libon et al., 2010). These profiles identify sub-groups of patients that can be grouped together either based on a more pronounced language or visuospatial deficit. It is because of this heterogeneity, along with the very limited number of pure amnestic patients with $\mathrm{MCI}$ in the current investigation, that their prognosis is uncertain. It is possible that some patients with MCI will go on to develop a non-AD syndrome (e.g. fronto-temporal dementia), longitudinal investigation would be needed to determine this. In spite of this limitation, what should be clear from the current data is that there are pronounced episodic memory deficits in both $\mathrm{MCI}$ and mild AD. These deficits are undoubtedly linked to pathological lesions at the medial temporal regions of interest. The neuropsychological evidence from the current investigation clearly suggests that semantic cognition is the next domain to become affected, potentially reflecting disease progression to the ATL and temporoparietal regions.

\section{Conclusion}

Overall, the current investigation demonstrates that in an old-age memory clinic, the most likely sequence of neuropsychological change is episodic memory dysfunction, followed by semantic cognition then by attention/executive dysfunction with relative sparing of visuospatial processing. This investigation also provides evidence for an effective neuropsychological test battery to assess patients with MCI. The test battery includes semantic cognition tests in addition to the traditional memory tests, as changes within this domain might be a sensitive indication of incipient $\mathrm{AD}$.

\section{Conflict of interest}

None declared.

Key points

- Amnestic MCI is relatively rare in an old-age memory clinic setting.

- Semantic cognition tends to be the next most severely affected domain following episodic memory in most patients.

- Attention, executive and visuospatial functions were relatively preserved.

- Cognitive deficits in this population fit with the pathological staging of $\mathrm{AD}$.

- Neuropsychological test batteries used to assess individuals at risk of $\mathrm{AD}$ (e.g. MCI patients) should include semantic cognition.

\section{Acknowledgements}

We are especially grateful to the patients and to their carers for taking part in this investigation. SFC was supported by an MRC capacity building studentship (to MALR, $\mathrm{KH}$ and $\mathrm{AB}$ ). 


\section{References}

Aggleton JP, Brown MW. 1999. Episodic memory, amnesia, and the hippocampalanterior thalamic axis. Behav Brain Sci 22: 425-444; discussion 444-489.

Aggleton JP, Brown MW. 2006. Interleaving brain systems for episodic and recognition memory. Trends Cogn Sci 10: 455-463.

Ahmed S, Mitchell J, Arnold R, Nestor PJ, Hodges JR. 2008. Predicting rapid clinical progression in amnestic mild cognitive impairment. Dement Geriatr Cogn Disord 25: $170-177$.

Backman L, Jones S, Berger AK, Laukka EJ, Small BJ. 2005. Cognitive impairment in preclinical Alzheimer's disease: a meta-analysis. Neuropsychology 19: 520-531.

Bancher C, Brunner C, Lassmann H, et al. 1989. Accumulation of abnormally phosphorylated tau precedes the formation of neurofibrillary tangles in Alzheimer's disease. Brain Res 477: 90-99.

Bancher C, Jellinger K, Lassmann H, Fischer P, Leblhuber F. 1996. Correlations between mental state and quantitative neuropathology in the Vienna Longitudinal Study on Dementia. Eur Arch Psychiatry Clin Neurosci 246: 137-146.

Baxter MG, Chiba AA. 1999. Cognitive functions of the basal forebrain. Curr Opin Neurobiol 9: 178-183.

Binder JR, Desai RH, Graves WW, Conant LL. 2009. Where is the semantic system? A critical review and meta-analysis of 120 functional neuroimaging studies. Cereb Cortex. 19(12): 2767-2796.

Bohnen NI, Kaufer DI, Ivanco LS, et al. 2003. Cortical cholinergic function is more severely affected in parkinsonian dementia than in Alzheimer disease: an in vivo positron emission tomographic study. Arch Neurol 60: 1745-1748.

Braak H, Braak E. 1991. Neuropathological stageing of Alzheimer-related changes. Acta Neuropathol Berl 82: 239-259.

Braak H, Braak E. 1998. Evolution of neuronal changes in the course of Alzheimer's disease. J Neural Transm Suppl 53: 127-140.

Caine D, Hodges JR. 2001. Heterogeneity of semantic and visuospatial deficits in early Alzheimer's disease. Neuropsychology 15: 155-164.

Corbett F, Jefferies E, Ehsan S, Lambon Ralph MA. 2009. Different impairments of semantic cognition in semantic dementia and semantic aphasia: evidence from the non-verbal domain. Brain 132: 2593-2608.

Coyle JT, Price DL, DeLong MR. 1983. Alzheimer's disease: a disorder of cortical cholinergic innervation. Science 219: 1184-1190.

Davis KL, Mohs RC, Marin D, et al. 1999. Cholinergic markers in elderly patients with early signs of Alzheimer disease. Jama 281: 1401-1406.

Deckersbach T, Dougherty DD, Savage C, et al. 2006. Impaired recruitment of the dorsolateral prefrontal cortex and hippocampus during encoding in bipolar disorder. Biol Psychiatry 59: 138-146.

DeKosky ST, Ikonomovic MD, Styren SD, et al. 2002. Upregulation of choline acetyltransferase activity in hippocampus and frontal cortex of elderly subjects with mild cognitive impairment. Ann Neurol 51: 145-155.

Delis DC, Kaplan E, Ober BA. 1987. California Verbal Learning Test; Adult Version; Research Edition: The Psychological Corporation.

Devlin JT, Russell RP, Davis MH, et al. 2000. Susceptibility-induced loss of signal: comparing PET and $\mathrm{fMRI}$ on a semantic task. Neuroimage 11: 589-600.

Deweer B, Lehericy S, Pillon B, et al. 1995. Memory disorders in probable Alzheimer's disease: the role of hippocampal atrophy as shown with MRI. J Neurol Neurosurg Psychiatry 58: 590-597.

Drzezga A, Lautenschlager N, Siebner H, et al. 2003. Cerebral metabolic changes accompanying conversion of mild cognitive impairment into Alzheimer's disease: a PET follow-up study. Eur J Nucl Med Mol Imaging 30: 1104-1113.

Dubois B, Feldman HH, Jacova C, et al. 2007. Research criteria for the diagnosis of Alzheimer's disease: revising the NINCDS-ADRDA criteria. Lancet Neurol 6: 734-746.

Dudas RB, Clague F, Thompson SA, Graham KS, Hodges JR. 2005. Episodic and semantic memory in mild cognitive impairment. Neuropsychologia 43: 1266-1276.

Edison P, Archer HA, Hinz R, et al. 2007. Amyloid, hypometabolism, and cognition in Alzheimer disease: an [11C]PIB and [18F]FDG PET study. Neurology 68: 501-508.

Eichenbaum H, Otto T, Cohen NJ. 1994. Two functional components of the hippocampal memory system. Behav Brain Sci 17: 449-517.

Fleischman DA, Gabrieli J. 1999. Long-term memory in Alzheimer's disease. Curr Opin Neurobiol 9: 240-244.

Folstein MF, Robins LN, Helzer JE. 1983. The Mini mental state examination. Arch Gen Psychiatry 40: 812.

Fox NC, Warrington EK, Freeborough PA, et al. 1996. Presymptomatic hippocampal atrophy in Alzheimer's disease: a longitudinal MRI study. Brain 119(Pt 6): 2001-2007.

Garrard P, Lambon Ralph MA, Watson PC, Powis J, Patterson K, Hodges JR. 2001. Longitudinal profiles of semantic impairment for living and nonliving concepts in dementia of Alzheimer's type. J Cogn Neurosci 13: 892-909.

Garrard P, Patterson K, Watson PC, Hodges JR. 1998. Category specific semantic loss in dementia of Alzheimer's type: functional-anatomical correlations from crosssectional analyses. Brain 121(Pt 4): 633-646.

Gilmor ML, Erickson JD, Varoqui H, et al. 1999. Preservation of nucleus basalis neurons containing choline acetyltransferase and the vesicular acetylcholine transporter in the elderly with mild cognitive impairment and early Alzheimer's disease. J Comp Neurol 411: 693-704.
Gron G, Wunderlich AP, Spitzer M, Tomczak R, Riepe MW. 2000. Brain activation during human navigation: gender-different neural networks as substrate of performance. Nat Neurosci 3: 404-408.

Herholz K. 2003. PET studies in dementia. Ann Nucl Med 17: 79-89.

Herholz K. 2008. Acetylcholinesterase activity in mild cognitive impairment and Alzheimer's disease. Eur J Nucl Med Mol Imaging 35(Suppl 1): S25-29.

Herholz K, Carter SF, Jones M. 2007. Positron emission tomography imaging in dementia. Br J Radiol 80(Spec No 2): S160-167.

Hodges JR, Erzinclioglu S, Patterson K. 2006. Evolution of cognitive deficits and conversion to dementia in patients with mild cognitive impairment: a very-longterm follow-up study. Dement Geriatr Cogn Disord 21: 380-391.

Hodges JR, Patterson K. 1995. Is semantic memory consistently impaired early in the course of Alzheimer's disease? Neuroanatomical and diagnostic implications. Neuropsychologia 33: 441-459.

Jack CR Jr, Lowe VJ, Senjem ML, et al. 2008. 11C PiB and structural MRI provide complementary information in imaging of Alzheimer's disease and amnestic mild cognitive impairment. Brain 131: 665-680.

Jefferies E, Lambon Ralph MA. 2006. Semantic impairment in stroke aphasia versus semantic dementia: a case-series comparison. Brain 129: 2132-2147.

Kennedy AM, Frackowiak RS, Newman SK, et al. 1995. Deficits in cerebral glucose metabolism demonstrated by positron emission tomography in individuals at risk of familial Alzheimer's disease. Neurosci Lett 186: 17-20.

Lambon Ralph MA, Patterson K, Graham N, Dawson K, Hodges JR. 2003. Homogeneity and heterogeneity in mild cognitive impairment and Alzheimer's disease: a cross-sectional and longitudinal study of 55 cases. Brain 126: 2350-2362.

Libon DJ, Xie SX, Eppig J, et al. 2010. The heterogeneity of mild cognitive impairment: a neuropsychological analysis. J Int Neuropsychol Soc 16: 84-93.

Lonie JA, Herrmann LL, Donaghey CL, Ebmeier KP. 2008. Clinical referral patterns and cognitive profile in mild cognitive impairment. Br J Psychiatry 192: 59-64.

McClelland JL, McNaughton BL, O'Reilly RC. 1995. Why there are complementary learning systems in the hippocampus and neocortex: insights from the successes and failures of connectionist models of learning and memory. Psychol Rev 102: 419-457.

McKenna P, Warrington E. 1983. The Graded Naming Test. Nelson: Berkshire.

McKhann G, Drachman D, Folstein M, et al. 1984. Clinical diagnosis of Alzheimer's disease: report of the NINCDS-ADRDA Work Group under the auspices of Department of Health and Human Services Task Force on Alzheimer's Disease. Neurology 34: 939-944.

Meyers J, Meyers K. 1995. Rey Complex Figure Test and Recognition Trial Professional Manual. Psychological Assesment Resources Inc.: Odessa, FL.

Minoshima S, Giordani B, Berent S, et al. 1997. Metabolic reduction in the posterior cingulate cortex in very early Alzheimer's disease. Ann Neurol. 42: 85-94.

Mioshi E, Dawson K, Mitchell J, Arnold R, Hodges JR. 2006. The Addenbrooke's Cognitive Examination Revised (ACE-R): a brief cognitive test battery for dementia screening. Int J Geriatr Psychiatry 21: 1078-1085.

Mummery CJ, Patterson K, Wise RJ, et al. 1999. Disrupted temporal lobe connections in semantic dementia. Brain 122(Pt 1): 61-73.

Nelson HE. 1976. A modified card sorting test sensitive to frontal lobe defects. Cortex 12: 313-324.

Nestor PJ, Fryer TD, Hodges JR. 2006. Declarative memory impairments in Alzheimer's disease and semantic dementia. Neuroimage 30: 1010-1020.

Nestor PJ, Fryer TD, Smielewski P, Hodges JR. 2003b. Limbic hypometabolism in Alzheimer's disease and mild cognitive impairment. Ann Neurol 54: 343-351.

Ouchi Y, Yoshikawa E, Futatsubashi M, et al. 2004. Activation in the premotor cortex during mental calculation in patients with Alzheimer's disease: relevance of reduction in posterior cingulate metabolism. Neuroimage 22: 155-163.

Parasuraman R, Nestor P. 1993. Attention and driving: assessment in elderly individuals with dementia. Clin Geriatr Med 9: 377-387.

Perry E, Walker M, Grace J. Perry R. 1999. Acetylcholine in mind: a neurotransmitter correlate of consciousness? Trends Neurosci 22: 273-280.

Perry RJ, Hodges JR. 1999. Attention and executive deficits in Alzheimer's disease: a critical review. Brain 122(Pt 3): 383-404.

Perry RJ, Watson P, Hodges JR. 2000. The nature and staging of attention dysfunction in early (minimal and mild) Alzheimer's disease: relationship to episodic and semantic memory impairment. Neuropsychologia 38: 252-271.

Petersen RC. 2004. Mild cognitive impairment as a diagnostic entity. J Intern Med 256: $183-194$.

Petersen RC, Doody R, Kurz A, et al. 2001. Current concepts in mild cognitive impairment. Arch Neurol 58: 1985-1992.

Petersen RC, Parisi JE, Dickson DW, et al. 2006. Neuropathologic features of amnestic mild cognitive impairment. Arch Neurol 63: 665-672.

Price JL, Morris JC. 1999. Tangles and plaques in nondemented aging and 'preclinical' Alzheimer's disease. Ann Neurol 45: 358-368.

Ries ML, Schmitz TW, Kawahara TN, et al. 2006. Task-dependent posterior cingulate activation in mild cognitive impairment. Neuroimage 29: 485-492.

Robertson IH, Ward T, Ridgeway V, Nimmo-Smith I. 1994. Test of Everyday Attention. Thames Valley Test Company: Bury St Edmunds.

Santacruz K, Lewis J, Spires T, et al. 2005. Tau suppression in a neurodegenerative mouse model improves memory function. Science 309: 476-481.

Sassin I, Schultz C, Thal DR, et al. 2000 Evolution of Alzheimer's disease-related cytoskeletal changes in the basal nucleus of Meynert. Acta Neuropathol Berl 100: 259-269. 
Scoville WB, Milner B. 2000. Loss of recent memory after bilateral hippocampal lesions. 1957. J Neuropsychiatry Clin Neurosci 12: 103-113.

Shoghi-Jadid K, Small GW, Agdeppa ED, et al. 2002. Localization of neurofibrillary tangles and beta-amyloid plaques in the brains of living patients with Alzheimer disease. Am J Geriatr Psychiatry 10: 24-35.

Snowden JS, Stopford CL, Julien CL, et al. 2007. Cognitive phenotypes in Alzheimer's disease and genetic risk. Cortex 43: 835-845.

Squire LR, Zola-Morgan S. 1991. The medial temporal lobe memory system. Science 253: $1380-1386$.

Stopford CL, Snowden JS, Thompson JC, Neary D. 2007 Distinct memory profiles in Alzheimer's disease. Cortex 43: 846-857.

Stopford CL, Snowden JS, Thompson JC, Neary D. 2008. Variability in cognitive presentation of Alzheimer's disease. Cortex 44: 185-195.

Stout JC, Bondi MW, Jernigan TL, et al. 1999 Regional cerebral volume loss associated with verbal learning and memory in dementia of the Alzheimer type. Neuropsychology 13: 188-197.

Thal DR, Rub U, Orantes M, Braak H. 2002. Phases of A beta-deposition in the human brain and its relevance for the development of AD. Neurology 58: $1791-1800$
Thal DR, Rub U, Schultz C, et al. 2000. Sequence of Abeta-protein deposition in the human medial temporal lobe. J Neuropathol Exp Neurol 59: 733-748.

Trenerry MR, Crosson B, DeBoe J, Leber WR. 1989. Stroop Neuropsychological Screening Test. Psychological Assessment Resources: Florida.

Troncoso JC, Martin LJ, Dal Forno G, Kawas CH. 1996. Neuropathology in controls and demented subjects from the Baltimore Longitudinal Study of Aging. Neurobiol Aging 17: 365-371.

Vann SD, Aggleton JP, Maguire EA. 2009. What does the retrosplenial cortex do? Nat Rev Neurosci 10: 792-802.

Visser M, Jefferies E, Lambon Ralph MA. 2010. Semantic processing in the anterior temporal lobes: a meta-analysis of the functional neuroimaging literature. J Cogn Neurosci 22: 1083-1094.

Wechsler D. 1997. Wechsler Memory Scale-Third Edition. The Psychological Corporation: San Antonio, TX.

Whitehouse PJ, Price DL, Struble RG, et al. 1982. Alzheimer's disease and senile dementia: loss of neurons in the basal forebrain. Science 215: 1237-1239.

Wilson RS, Sullivan M, de Toledo-Morell L, et al. 1996. Association of memory cognition in Alzheimer's disease with volumetric estimates of temporal lobe structures. Neuropsychology. 10: 459-463. 